\title{
Vibroacoustic Measurements in a Transient State of Transformer Operation
}

\author{
S. BORUCKI* \\ Faculty of Electrical Engineering, Automatic Control and Computer Science, Opole University of Technology \\ Mikołajczyka 5, 45-271 Opole, Poland
}

\begin{abstract}
The subject matter of this paper refers to the assessment of the technical condition of a power transformer core and windings based on vibroacoustic measurements taken during a transient operation state of the appliance diagnosed - at a transformer unit switch on. The paper presents preliminary results of the research work carried out, which aims at elaborating a new diagnostic and assessment method of the degree of the transformer core and winding pressing using the so-called modified vibroacoustic method. The paper characterizes the measurement path and the assessment method of the core and winding pressing degree based on the selected analyses of the vibroacoustic signal registered. The original research results presented in the paper were obtained at a real $400 \mathrm{kV} \mathrm{A}$ power transformer switch on in laboratory conditions - for a regular operation condition and for modeled core damage.
\end{abstract}

PACS numbers: 43.40.-r, 43.40.Vn, 43.58.Wc

\section{Introduction}

Power transformers are elements of the electric power system of essential significance for electric energy transfer and distribution, the emergency switch-off of which may cause considerable economic losses [1-3]. During a regular operation a transformer unit is subjected to the influence of many unfavorable factors, which shorten a transformer service time and may cause unexpected disastrous failures. In reference to the transformer active part, magnetostrictive vibrations and cellulose depolarization are the most harmful factors, which cause the loss of insulating board mechanical strength. They also cause a gradual loosening of the core and winding pressing and clamping, which results in weakening of the active part mechanical construction. This is especially important in the case of the units being in operation for over 20 years, in which, during an internal inspection, we often observe fallen out distance inserts, wedges and clamping screws. Such condition of a transformer construction is characteristic of a decreased mechanical resistance to dynamic short-circuit forces and the occurrence of local core overheating, which, in consequence, may lead to a disastrous failure - damage of a transformer unit.

In power sector, the assessment of the pressing degree of the core and winding is carried out first of all based on the measurements of: magnetizing currents, frequency response analysis (FRA) and acoustic pressure generated by an operating transformer at a changing load [4-6].

*e-mail: s.borucki@po.gmail.com
There is also an analysis method of the transformer construction vibrations, the so-called classical vibroacoustic method $[1,7,8]$, which consists in vibration measurement and analysis of the object under study during its regular operation. Nevertheless, the above-given measurement methods enable identification of the cases only of an extreme loosening of the active part elements. Presently, the only effective way of identifying the core and winding loosening is internal inspection, which is rather a complex and expensive procedure.

The research work carried out in the Institute of Power Engineering of Opole University of Technology, the preliminary results of which are presented in this paper, aim at development of a new method of diagnostics and assessment of the degree of pressing of the cores and windings of power transformers. The method suggested by author, the so-called modified vibroacoustic method, is based on the measurements of mechanical vibrations of the transformer diagnosed in a transient state of a transformer - at a transformer unit switch on. Hence the aim of the research work carried out is development of an innovative and non-invasive assessment methodology of the technical condition of the cores and windings of transformer units operating in the national electric power system.

\section{Characteristics of the object under study and the measuring apparatus used}

The investigation results presented in this paper were obtained based on the analysis of the tub mechanical vibrations registered at a testing station, which were mea- 
sured during switching on a real $400 \mathrm{kV}$ A power transformer. Table lists the most significant technical parameters of the power object under study and Fig. 1a presents its overall view.

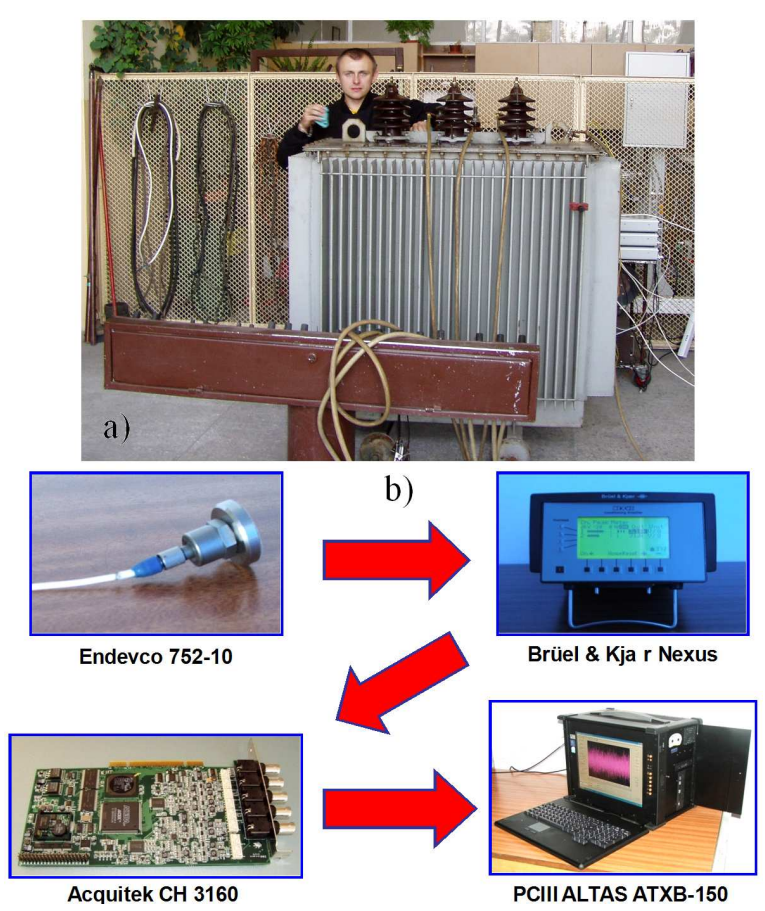

Fig. 1. Overall view of the transformer under study (a) and of the measurement path applied (b).

TABLE

Selected technical parameters of the power object under study.

\begin{tabular}{l|c}
\hline \hline \multicolumn{1}{c|}{ Parameters } & Values \\
\hline power & $400 \mathrm{kV} \mathrm{A}$ \\
primary voltage $\left(U_{1}\right)$ & $15.75 \mathrm{kV}$ \\
secondary voltage $\left(U_{2}\right)$ & $0.4 \mathrm{kV}$ \\
short-circuit voltage $\left(U_{\mathrm{zw}}\right)$ & $4.5 \%$ \\
idle loss $\left(P_{j}\right)$ & $1.02 \mathrm{~kW}$ \\
load loss $\left(P_{\text {obc }}\right)$ & $4.80 \mathrm{~kW}$ \\
connection group & Dy5 \\
year of manufacture & 1978
\end{tabular}

Mechanical vibrations of the transformer were measured by an accelerometer type $752-10$ by Endevco company, which was attached to the tub wall with a magnet. The signal received by a transducer was passed on the input of a low-noise measuring amplifier series Nexus by Brüel \& Kjær company. In order to become separated from interference transferred by a low-voltage network, the amplifying system was supplied from the internal battery source during measurement taking. A computer equipped with a measuring card type $\mathrm{CH} 3160$ by Acquitek company and specialized AcquiFlex software were used for observation and registration of the vibration signals measured $[1,2,9]$. Figure $1 \mathrm{~b}$ shows the view of the measurement path applied.

\section{The analysis of the results obtained}

The range of the research experiment carried out within this paper included registration and analysis of the tub mechanical vibrations of the transformer unit diagnosed for two extreme operation modes: regular operation (with a turned core) and with a modeled core defect (with a loosened core). The core defect was modeled during an internal inspection of the transformer, during which the screws pressing the upper and lower yoke beam were significantly loosened. The assessment of the registered vibroacoustic vibrations of the unit under study was carried out based on the analyses:

- time analysis,

- frequency analysis,

- time-frequency analysis or

- steady-state conditions of the selected vibration harmonics.

Figure 2 shows time runs of mechanical vibrations of the transformer under study, which were registered during its switching on to the idle work state: for the case with a turned core (Fig. 2a) and with a loosened core (Fig. 2b). It results from the time run analysis that loosening of the core of the object under study significantly influences the amplitude value of the vibrations registered. Additionally, the process of vibration stabilization of the diagnosed transformer with a modeled core defect is characteristic of a significant longer time interval than in the case of a properly pressed core.

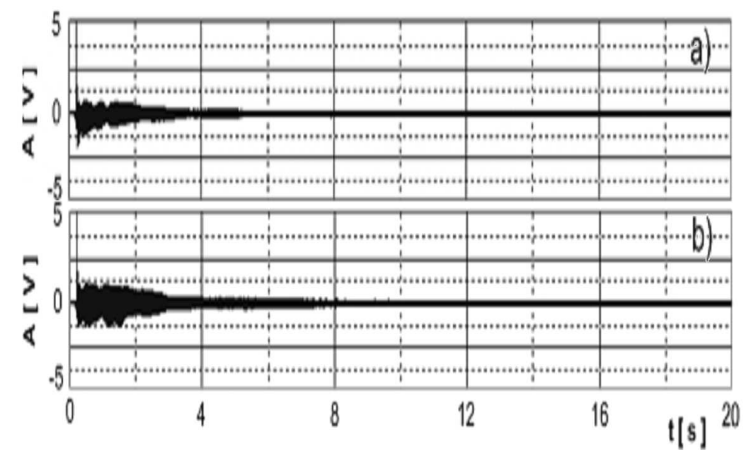

Fig. 2. Exemplary time runs of the vibroacoustic vibrations registered: (a) turned core, (b) loosened core.

Figure 3 shows the frequency analysis results of the vibrations measured, which were determined for moment $t=1 \mathrm{~s}$ since the moment of switching on the transformer. The characteristics presented indicate that in the case of switching on the transformer with a loosened core (Fig. 3b) the particular frequency components of the vibrations registered are characteristic of a significantly bigger amplitude than the components obtained during switching on the unit with a turned core 
(Fig. 3a). Additionally, based on the analysis of the frequency spectrum determined in Fig. $3 \mathrm{~b}$, the occurrence of elevated amplitudes of frequency components from the band $2000 \div 2800 \mathrm{~Hz}$ was observed.

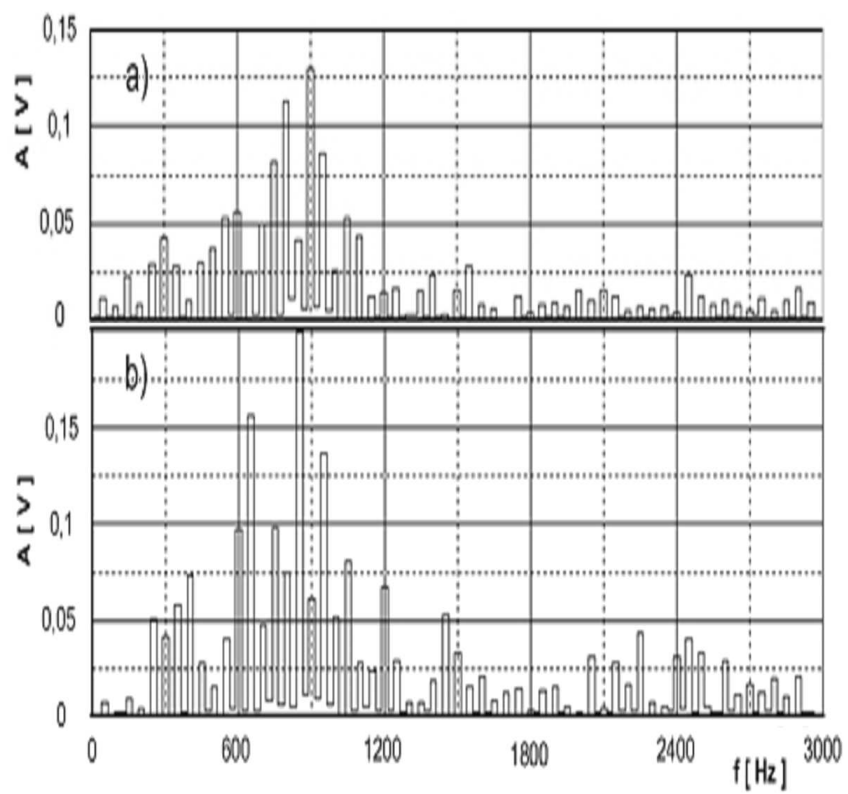

Fig. 3. Exemplary amplitude spectra of the vibroacoustic signals registered determined for moment $t=1 \mathrm{~s}$ since switching on the transformer unit under study: (a) turned core, (b) loosened core.

The spectrograms of the vibroacoustic signals registered, shown in Fig. 4, supplement the spectrum analysis. The time-frequency images shown in the figure below show that the participation of frequency components of the vibrations measured during switching on the transformer with a loosened core (Fig. 4b) are characteristic of a much wider band and clearly longer time of achieving a steady-state condition by the unit. The comparison of the spectrograms determined for the transformers with a turned core (Fig. 4a) and a loosened core (Fig. 4b) also indicates that the amplitudes of the particular components of the spectrum determined for the operation with the loosened core have significantly bigger amplitudes. The research results obtained based on the time-frequency analysis confirm the earlier obtained results of the analyses in the time and frequency domains.

The last of the analyses carried out was the assessment of the decay or achieving the steady-state condition of the selected frequency components of the tub mechanical vibrations registered. Twenty harmonic components, which were characteristic of the biggest amplitude participation in the spectrum, were selected to carry out this assessment based on the frequency and timefrequency analyses presented. Harmonics from the range $300 \div 1250 \mathrm{~Hz}$ were assumed as representative components of the vibroacoustic signals of the power object diagnosed.

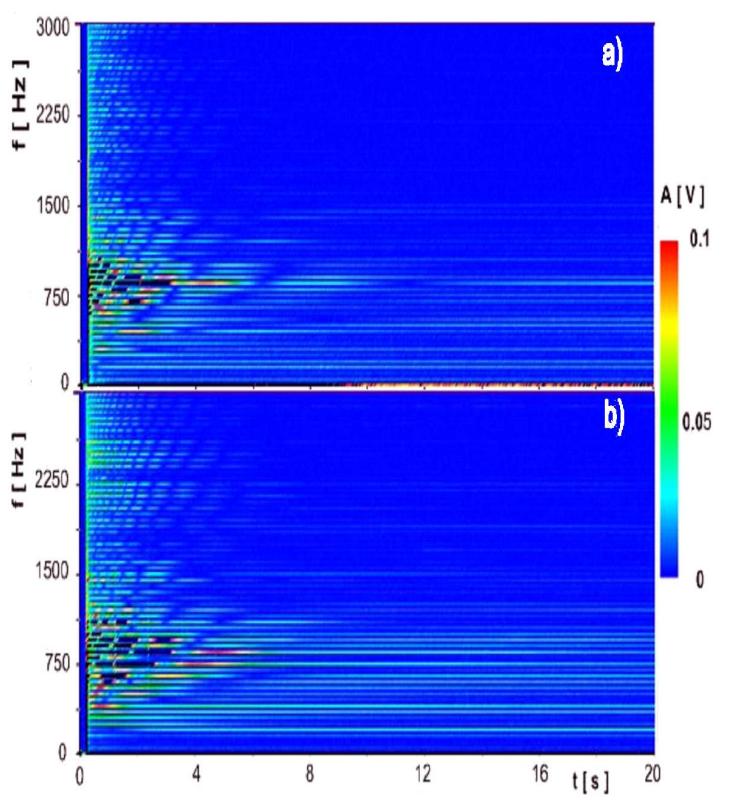

Fig. 4. Exemplary spectrograms of the vibroacoustic signals registered for: (a) turned core, (b) loosened core.

Figure 5 compares in a graphic way comparative time values which are needful for achieving the steady-state condition or decay by selected frequency components of vibrations. Figure 5 shows the results obtained during switching on the transformers with turned and loosened cores.

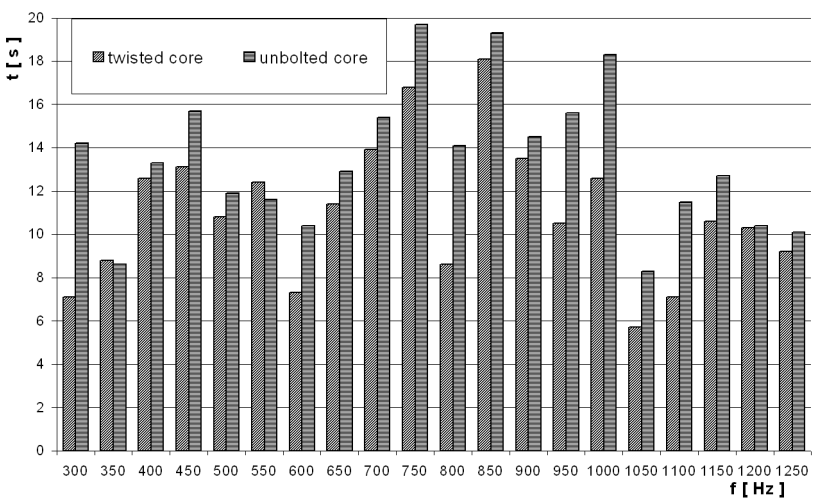

Fig. 5. Time of the steady-state condition or decay of the selected vibration harmonics.

Based on the results shown in Fig. 5 it can be observed that the process of switching on the transformer with loosened screws packeting the core is characteristic of elevated time interval values compared with an analogous test but with a turned core. The results obtained based on the above-presented analysis, jointly with the analysis results in the time, frequency and time-frequency analyses, may constitute a set of vibroacoustic descriptors used in diagnostics and assessment of the technical condition of the cores and windings of power transformers. 


\section{Summing up}

Based on the transformer core vibration analyses in the time, frequency and time-frequency domains for two cases of transformer operation, significant differences in characteristics and vibroacoustic indicators were indicated for transformers with the turned and loosened cores. The differences observed in time runs, frequency participation and time-frequency images may, with a large degree of probability, be used in the future for development of an innovative identification method of the core and transformer winding loosening. Therefore the research work carried out within this paper makes it possible to formulate the following inferences:

- the application of the vibroacoustic method for the measurements of mechanical vibrations of transformer units during a "non-steady" operation may enable diagnostics of the pressing state of their cores and windings,

- in order to develop detailed assessment criteria of a transformer technical condition using the modified vibroacoustic method it is necessary to create a data base containing the results and analyses of the vibration measurements taken for various unit types and constructions,

- achieving a high identification effectiveness of the core and winding damage using the method suggested is conditioned by carrying out many experimental investigations on real objects of professional power engineering.

\section{References}

[1] S. Borucki, T. Boczar, A. Cichoń, Energetyka XI, 39 (2007) (in Polish).

[2] E. Grossman, K. Feser, in: Proc. Int. Conf. APTADM, Wrockaw (Poland 2001), p. 264.

[3] S. Borucki, A. Cichoń, T. Boczar, Pomiary Automatyka Kontrola 1, 19 (2009). (in Polish).

[4] S. Borucki, T. Boczar, A. Cichoń, M. Lorenc, Przeglad Elektrotechniczny 3, 27 (2007) (in Polish).

[5] A. Szpakowski, C. Tyszkiewicz, T. Pustelny, Acta Phys. Pol. A 114, A-239 (2008).

[6] M. Szmechta, D. Zmarzły, T. Boczar, M. Lorenc, Acta Phys. Pol. A 114, A-231 (2008).

[7] R. Malewski, J. Subocz, M. Szrot, J. Płowucha, R. Zaleski, Energetyka 12, 884 (2006) (in Polish).

[8] F. Witos, Z. Gacek, Z. Opilski, Acta Phys. Pol. A 114, A-249 (2008).

[9] Exploitation of Transformers, Ed. J. Subocz, Energo-Complex, Wrocław 2007 (in Polish). 